\title{
RETRACTION NOTICE TO \\ "COMPANY FINANCIAL PATH ANALYSIS USING \\ FUZZY C-MEANS AND ITS APPLICATION IN FINANCIAL FAILURE PREDICTION" [JOURNAL OF BUSINESS ECONOMICS AND MANAGEMENT, 19(1), 213-234, 2018].
}

\author{
Jiaming Liu, Chong Wu \\ Harbin Institute of Technology, School of Management, Harbin, Hei Longjiang, China \\ Received 15 September 2017; accepted 07 December 2017
}

The following article will be retracted from publication in Journal of Business Economics and Management: Company financial path analysis using fuzzy c-means and its application in financial failure prediction by Jiaming Liu and Chong Wu, Volume 19, Issue 1, pp. 213-234, Journal of Business Economics and Management, 2018, https://doi.org/10.3846/16111699.2017.1415959

https://journals.vgtu.lt/index.php/JBEM/article/view/1606

Received 17 September 2017, accepted 7 December 2017,

since there are presented some paraphrased ideas with slight changes from published article

Predicting corporate bankruptcy using a self-organizing map: An empirical study to improve the forecasting horizon of a financial failure model, by Philippe du Jardin and Eric Séverin, Volume 51, Issue 3, pp. 701-711, Decision Support Systems, 2011,

https://doi.org/10.1016/j.dss.2011.04.001

Received 15 September 2010, accepted 11 April 2011.

The Editors and publishers of the journal, Vilnius Gediminas Technical University, note that we received, peer-reviewed, accepted and published the article on the basis that the authors are presenting original results.

The retracted article will remain online to maintain the scholarly record, but it will be digitally watermarked on each page as "retracted". 